\title{
Ensino da Justiça: Motivação de Docentes do Ensino Fundamental
}

\author{
Leandra Lúcia Moraes Couto ${ }^{1}$ \\ Programa de Pós-Graduação em Psicologia da Universidade Federal do Espírito Santo, \\ Vitória, ES, Brasil \\ Heloisa Moulin de Alencar \\ Departamento de Psicologia Social e do Desenvolvimento da Universidade Federal \\ do Espirito Santo, Vitória, ES, Brasil \\ Programa de Pós-Graduação em Psicologia da Universidade Federal do Espírito Santo, \\ Vitória, ES, Brasil \\ Tatiana Machado Moraes \\ Programa de Pós-Graduação em Psicologia da Universidade Federal do Espírito Santo, \\ Vitória, ES, Brasil
}

\section{Resumo}

No presente estudo, buscou-se investigar se professoras de $1^{\circ}$ e de $5^{\circ}$ ano do ensino fundamental consideram que ensinam a justiça em suas práticas pedagógicas e, se positivo, qual a motivação para ensinar este valor moral. Além disso, foram averiguadas as diferenças entre os dados das docentes de $1^{\circ}$ e de $5^{\circ}$ ano, no que diz respeito aos dois objetivos anteriormente mencionados. Para tanto, foram realizadas entrevistas semiestruturadas, individuais, tendo como referência o método clínico piagetiano. Verificou-se que todas as participantes consideram que ensinam a justiça. A maioria das docentes ensina o referido valor moral pelo fato de essa ser uma responsabilidade da escola ou devido à carência desse papel por parte da família. Além destas, foram constatadas motivações que dizem respeito à crise de valores presente na atualidade, à importância da justiça para a sociedade, à possibilidade de expansão de si, entre outras. Com relação às diferenças entre os anos escolares pesquisados, averiguou-se que as docentes que trabalham com o $1^{\circ}$ ano tendem a justificar o ensino da justiça predominantemente devido ao fato de esta ser uma prática de responsabilidade da escola. Por sua vez, as professoras que lecionam para o $5^{\circ}$ ano parecem ensinar a justiça porque esta prática pode favorecer a convivência em sociedade, as relações humanas. A partir dos resultados, enfatiza-se a necessidade de trabalhos contínuos de ensino da justiça, pensados e programados para desenvolver indivíduos autônomos.

Palavras-chave: Psicologia da moralidade, educação em valores morais, justiça, prática docente.

\section{Justice Teaching: Motivation of Elementary School Teachers}

\begin{abstract}
In the present study, we sought to investigate whether teachers of the 1st and 5th year of elementary school consider they teach justice in their educational practices and, if so, what is the motivation to teach

1 Endereço para correspondência: Universidade Federal do Espírito Santo, Centro de Ciências Humanas e Naturais, Departamento de Psicologia Social e do Desenvolvimento, Programa de Pós-Graduação em Psicologia, Av. Fernando Ferrari, 514, Goiabeiras, Vitória, ES, Brasil 29075-910. Fone: (27) 4009-2505; Fax: (27) 4009-2501. E-mail: leandrabj@hotmail.com, heloisamoulin@gmail.com e tatianam.moraes@gmail.com Agradecemos ao Fundo de Apoio à Ciência e Tecnologia de Vitória (Facitec) pelo apoio financeiro. Este estudo é decorrente da dissertação de mestrado da primeira autora sob orientação da segunda.
\end{abstract}


this moral value. Besides, the differences among the data from the teachers of the 1st and 5th year were probed. For this, semi-structured, individual interviews with the reference of the Piagetian clinical method were done. It was verified that all participants consider that they teach justice. Most teachers teach the said moral value because this is a responsibility of the school or due to lack of this role by the family. Likewise motivations related to the crisis of values in this present time, the importance of justice for society, the possibility of expanding itself, among others were found. Regarding the differences between the school years studied, it was established that the teachers who work with the 1st year tend to justify the teaching about justice predominantly due to the fact that this is a practice of the school's responsibility. In turn, the teachers who teach the 5th year seem to teach justice because this practice can promote coexistence in society, human relationships. From the results, the need for continuous education on the teaching of justice, designed and programmed to develop autonomous individuals is emphasized.

Keywords: Psychology of morality, education in moral values, justice, teaching practice.

\section{Enseñanza de la Justicia: Motivación del Docente de la Educación Primaria}

\section{Resumen}

En el presente estudio, se investigó si profesoras de $1^{\circ}$ y de $5^{\circ}$ grado de la educación primaria consideran que enseñan la justicia en sus actividades pedagógicas y, si es positivo, cuál es la motivación para enseñar este valor moral. Además, se averiguaron las diferencias entre los datos de las docentes de $1^{\circ}$ y de $5^{\circ}$ grado, en cuanto a los dos objetivos anteriormente mencionados. Con este fin, se realizaron entrevistas semiestructuradas, individuales, bajo el método clínico piagetiano. Se verificó que todas las participantes consideran que enseñan la justicia. La mayoría de las docentes enseña dicho valor moral por el hecho de que es una responsabilidad de la escuela o por la falta de este papel por parte de la familia. Además de estas, se constataron motivaciones que se refieren a la crisis de valores presentes en la actualidad, a la importancia de la justicia para la sociedad, a la posibilidad de expansión de sí, entre otras. En relación a las diferencias entre los grados escolares investigados, se averiguó que las docentes que trabajan en el $1^{\circ}$ grado tienden a justificar la enseñanza de la justicia predominantemente debido al hecho de que esta es una práctica de responsabilidad de la escuela. Al mismo tiempo, parece que las profesoras del $5^{\circ}$ grado enseñan la justifica porque esta práctica puede favorecer a la convivencia en sociedad, a las relaciones humanas. A partir de los resultados, se enfatiza en la necesidad de trabajos continuos de enseñanza de la justicia, pensados y programados para desarrollar individuos autónomos.

Palabras clave: Psicología de la moralidad, educación en valores morales, justicia, práctica docente.

O presente trabalho aborda uma pesquisa na área da educação moral, que corresponde às práticas que visam constituir sujeitos autônomos, aptos à cooperação (Piaget, 1930/1996). Nessa perspectiva, há a concepção de que os valores morais não são inatos, mas construídos no processo de desenvolvimento dos indivíduos. Assim, tal formação moral pode acontecer em diversos espaços sociais nos quais o indivíduo está inserido: na família, na escola, nos círculos de amizade, na igreja, entre outros (Müller \& Alencar, 2012).
O livro "O Juízo Moral na Criança", de Jean Piaget (1932/1994), é obra pioneira nos estudos sobre o juízo moral. Em consonância com sua teoria do conhecimento, no que se refere ao estudo do juízo moral, Piaget (1932/1994) objetivou estudar o sujeito epistêmico, ou seja, o que é comum aos indivíduos. O desenvolvimento moral, assim como o desenvolvimento cognitivo, é visto por este autor como fruto de uma construção, de uma constante auto-organização, a qual ocorre em contextos de interação social. 
A partir dos resultados de seus estudos sobre a moralidade, Piaget (1932/1994) concluiu que há um desenvolvimento do juízo moral, caracterizado pela evolução de duas tendências morais: heteronomia e autonomia. Conforme o aludido autor, até os quatro anos de idade, aproximadamente, as crianças estão em uma fase de anomia, pois não possuem a consciência das regras, e sim hábitos de conduta. Após esse período, as crianças passam a compreender a dimensão do dever, do bem e do mal, portanto, a moral começa a fazer parte do seu universo de valores. Nesse momento, então, inicia-se a fase de heteronomia, a qual ocorre até os nove anos, aproximadamente. Nela, a moral é a do respeito unilateral, pois a fonte de legitimação das regras caracteriza-se pela referência à autoridade. Portanto, é considerado correto o ato que está de acordo com as regras impostas pela figura de autoridade. A partir desse tipo de relação é que a criança adentra ao mundo da moralidade e desenvolve o sentimento de obrigatoriedade, o qual equivale a um mandamento de consciência que impele o indivíduo a agir de determinada maneira (La Taille, 2006; Piaget, 1932/1994). Por sua vez, em torno dos nove anos de idade, a partir da vivência de relações de reciprocidade, a criança pode apresentar sinais de autonomia. A moral autônoma é a moral da justiça e do respeito mútuo, em que prevalecem as relações de cooperação. Nesta fase, a criança liberta-se da obediência estrita às regras e passa a julgar a partir de princípios, isto é, compreendendo e interpretando as regras.

Vale dizer que, para Piaget (1932/1994), as duas tendências morais ocorrem sempre na mesma sequência: para alcançar a autonomia, necessariamente é preciso passar pela heteronomia. Além disso, o autor afirma que nenhum indivíduo é totalmente heterônomo ou autônomo, o que há é uma tendência pela qual se pensa a moral.

Com base nas ideias piagetianas, Lawrence Kohlberg (1992) aprofundou o estudo do desenvolvimento moral por meio da identificação de níveis e estágios deste tipo de desenvolvimento. Para este autor, assim como para Piaget (1932/1994), a disposição de estágios é invariante e universal, apesar de nem todos atingirem aqueles mais elevados. Kohlberg (1992) apresenta uma conceituação mais discriminada dos estágios de desenvolvimento moral do que Piaget (1932/1994), pois propõe a existência de seis estágios, incluídos em três níveis: pré-convencional, estágios 1 e 2 ; convencional, estágios 3 e 4; e pós-convencional, estágios 5 e 6 .

No nível pré-convencional, os sujeitos ainda não entendem e não respeitam normas morais e expectativas compartilhadas, ao contrário, interpretam os rótulos de bom e mau, certo e errado, de acordo com as consequências da ação. Este nível é dividido em dois estágios: "orientação para a punição e a obediência" e "hedonismo instrumental relativista". No primeiro, a moralidade de uma ação é definida em termos das consequências físicas para o agente. Já no segundo, a ação correta é aquela que serve como instrumento para satisfazer as necessidades do indivíduo. Com relação ao nível convencional, a moralidade consiste em um sistema de regras morais e normas socialmente compartilhadas. Neste nível, há também dois estágios: "moralidade do bom garoto, de aprovação social e relações interpessoais" e "orientação para a lei e a ordem". No primeiro estágio, o bom comportamento é aquele que tem a aprovação dos outros, enquanto no segundo o comportamento correto consiste em mostrar respeito pela autoridade e por regras fixas, e em manter a ordem social. No último nível, pós-convencional, há um esforço em definir valores e princípios morais que tenham validade e aplicação. Assim como os demais níveis, este, também, possui dois estágios: "orientação para o contrato social" e "princípios universais de consciência". No primeiro, as leis não são mais consideradas válidas por si mesmas. $\mathrm{O}$ ato correto é definido em termos de direitos individuais e gerais. Por sua vez, no segundo estágio, o pensamento pós-convencional atinge seu nível mais alto, sendo que o indivíduo reconhece os princípios morais universais da consciência individual e age de acordo com eles (Biaggio, 2006; Kohlberg, 1992; La Taille, 2006).

La Taille é outro autor que tem dedicado seus estudos à área da Psicologia da Moralidade. $\mathrm{O}$ referido autor propõe uma articulação entre as dimensões intelectuais e afetivas presentes na moralidade, sem que estas se reduzam uma 
à outra. Assim, La Taille (2006) busca contribuir para a questão que, segundo ele, Kohlberg (1992) e Piaget (1932/1994) deixaram em aberto: a necessidade de identificar as raízes afetivas da ação moral.

Segundo La Taille (2006), para compreender os comportamentos morais dos sujeitos, é preciso conhecer a perspectiva ética que estes adotam. Nesse sentido, o autor estabelece definições distintas para os conceitos de moral e ética, considerando que essa diferenciação é essencial para a compreensão psicológica das condutas morais. Conforme afirma La Taille (2006), tais palavras são frequentemente empregadas como sinônimas. No entanto, para ele, a moral corresponde a deveres, princípios e regras, e os conteúdos do plano moral estão vinculados às possibilidades de resposta à pergunta "como devo agir?" (p. 29). Por outro lado, a ética equivale à busca de uma vida boa, sendo que à reflexão ética cabe a resposta à pergunta "que vida eu quero viver?" (p. 29).

Assim, La Taille (2006) afirma a existência de um plano moral e outro ético. O plano moral é o lugar do sentimento de obrigatoriedade, ou dever, o qual corresponde a uma exigência, de ordem pessoal ou social, que impele o indivíduo a agir de determinadas formas. Com relação ao plano ético, o invariante psicológico corresponde à busca de sentido para a vida que, por sua vez, possui outro invariante: o sentimento de expansão de si próprio, o qual equivale à busca e manutenção de representações de si com valor positivo. Os planos moral e ético são complementares e indissociáveis, e a articulação destes é estabelecida por meio do autorrespeito, que corresponde a todo estado subjetivo de valorização de si próprio quando regido pela moral.

No que diz respeito aos conteúdos dos planos moral e ético, eles podem ser os mais variados. Portanto, La Taille (2006) ressalta que "devemos definir conteúdos para a moral, pois é ela que confere às 'opções de vida boa' a sua legitimidade, isto é, confere-lhes as condições necessárias para que mereçam o nome de ética" (p. 60). Dessa maneira, pode-se notar que não é qualquer sistema de representações de si que poderá ser chamado de ético.
A esse respeito, La Taille (2009), com base em Piaget (1954/1962), afirma que tudo pode tornar-se valor, tendo em vista que tudo é passível de investimento afetivo. Os valores são a energética da vida em geral e, portanto, da vida moral. Assim, três tipos de valores podem compor as representações de si: valores que não possuem relação com a moral, valores contraditórios com as leis morais e valores coerentes com a moral (La Taille, 2001). Nesse sentido, para a personalidade merecer ser considerada como ética dependerá dos valores que são centrais nas representações de si dos indivíduos. Assim, La Taille (2006) afirma que as opções morais de uma pessoa dependem das respostas que esta forneceu no plano ético.

Isto posto, averigua-se um importante aspecto a ser refletido no que diz respeito ao contexto social atual. Conforme expõe La Taille (2009), vive-se, na atualidade, uma "cultura do tédio", em que se verifica um tédio existencial, isto é, uma ausência de direção e de razão para viver. Fato este que pode ser constatado na alta frequência de suicídios e na alta incidência da depressão (La Taille, 2009, 2011). Desse modo, o referido autor (2011, p. 70) conclui que "estamos em tempos de 'mal-estar-ético', pois não usufruímos de uma "vida boa". Embora este quadro seja evidentemente negativo, La Taille $(2009,2011)$ parte do pressuposto de que não se está paralisado no que se refere a perspectivas educacionais. Para ele, se é verdade que se vive em uma cultura do tédio e da vaidade, é, em certa medida, por desperdiçar oportunidades que estão ao alcance.

Nessa mesmalinha, encontra-se também uma importante reflexão em La Taille e Menin (2009) acerca da possível vivência na sociedade de um momento de "crise de valores" ou de "valores em crise". Conforme expõem os autores (p. 9), "crise de valores" carrega a noção de que os valores morais estariam "doentes" e, portanto, correndo perigo de extinção. "Valores em crise", por sua vez, carrega a noção de que os valores morais não desapareceram, mas estariam mudando de interpretação.

Tal discussão é relevante para a área da Psicologia da Moralidade e da Educação em valores 
morais, e merece ser abordada nas pesquisas dos referidos campos de conhecimento.

Assim, com La Taille (2009), defende-se que os responsáveis pela educação moral de crianças e de jovens devem empenhar-se para que as novas gerações penetrem numa cultura de sentido. Este autor propõe que, por meio da educação moral, promova-se "a valorização da busca da verdade, do pensar bem, da boa fé, pois, se não o fizermos, privamos a moralidade das exigências intelectuais e atitudes necessárias à sua construção e evolução" (p. 224). O referido autor ressalta, também, a importância de se preservar a memória, as referências ao passado, e destaca a necessidade de articulação entre conhecimento e sentido, pois esta permite pensar o viver em suas variadas dimensões. De acordo com La Taille (2009), a educação moral pressupõe, ainda, o cuidar das crianças e dos jovens, fazendo-os crescer e desenvolver a autonomia.

Puig (2007) também discute a respeito das finalidades da educação em valores. Para ele, esta formação deve propiciar aprendizagens éticas, ou seja, deve possibilitar ao indivíduo aprender a viver. Nesta perspectiva, aprender a viver pressupõe "aprender a ser", "aprender a conviver", "aprender a participar" e "aprender a habitar o mundo". "Aprender a ser" diz respeito a construir uma ética pessoal, uma ética de si mesmo, que deve incluir a formação de um pensamento autônomo e crítico, que faça o indivíduo ser capaz de construir critérios próprios de conduta; reforce a vontade e a autorregulação; exercite a auto-observação e incremente a consciência de si mesmo. "Aprender a conviver" diz respeito à tarefa formativa para superar a tendência à separação e ao isolamento entre pessoas, ajudando os indivíduos a estabelecer vínculos pessoais baseados na compreensão do outro e no compromisso com projetos em comum. "Aprender a participar" é a aprendizagem da vida em comum, ou seja, é trabalhar por uma ética que torne os indivíduos cidadãos ativos, participativos. "Aprender a habitar o mundo" é a proposta de um trabalho educativo reflexivo sobre a responsabilidade pelo presente e pelo futuro do planeta, ou seja, que nos faça reaprender uma maneira sustentável de habitar o mundo.
É notório, no entanto, que pais e profissionais da educação, muitas vezes, não concordam sobre a quem compete o ensino dos valores morais, ou sobre o quanto cabe a um ou ao outro o papel de aplicar a educação em valores morais. Diante disso, afirma-se, com Dessen e Polonia (2007), que ambas as instituições são fundamentais para desencadear os processos evolutivos das pessoas, e atuam como propulsoras ou inibidoras de seu crescimento físico, intelectual, emocional e social. Nesse sentido, as autoras ressaltam que é imprescindível a implementação de políticas que assegurem a aproximação entre estes dois contextos. Também García e Puig (2010) destacam a importância do envolvimento das famílias na escola. Os autores descrevem alguns resultados positivos deste envolvimento, como a melhora da autoestima dos alunos, a melhora do rendimento escolar dos educandos e a diminuição das taxas de ausência e evasão escolar. Para eles, incorporar as famílias à dinâmica escolar é um dos mais importantes desafios que o sistema educativo enfrenta. Diante disso, afirmam que tal incorporação é um processo que requer tempo e dedicação e, além de ser demorado, deve ser abordado coletivamente.

Apesar de se reconhecer a função particular da escola e da família na formação moral dos indivíduos, concorda-se com autores (García \& Puig, 2010; La Taille, 2009; Piaget, 1930/1996; Puig, 1998, 2007) que afirmam que o contexto escolar é um espaço privilegiado para educar moralmente. Além dos autores citados, encontra-se na legislação brasileira, por meio dos Parâmetros Curriculares Nacionais - PCNs (Secretaria de Educação Fundamental, 2000), a indicação de inclusão do ensino de valores no contexto escolar. Vale dizer que um dos fatores que estabelece a escola como local distinto para educar moralmente refere-se ao fato de que o exercício da moralidade no espaço privado, ou seja, na família, não contempla todas as características de seu exercício no espaço público (La Taille, 2009). Sobre este assunto, La Taille (2009) assinala que o espaço do exercício da cidadania é, justamente, o espaço público. Além disso, entende-se que tal formação deve ocorrer neste contexto de forma orientada e programa- 
da, por meio de propostas concretas (La Taille, 2009; Puig, 1998, 2007).

Com relação aos temas a serem utilizados na condução de práticas de educação em valores morais no contexto escolar, a legislação brasileira e diferentes autores descrevem uma diversidade de assuntos que podem ser adotados. Conforme orientações dos PCNs (Secretaria de Educação Fundamental, 2000), a educação para a cidadania requer que questões sociais sejam apresentadas para a aprendizagem e reflexão dos educandos. Nesse sentido, no referido documento há a proposta de incluir questões sociais no currículo escolar, sendo eleitos cinco Temas Transversais, além da indicação de trabalho com Temas Locais. São eles: Ética, Meio Ambiente, Pluralidade Cultural, Saúde e Orientação Sexual. No que diz respeito ao tema Ética, foram eleitos quatro conteúdos de trabalho: respeito mútuo, justiça, diálogo e solidariedade. Além dos referidos temas, Puig (2007) ressalta a possibilidade de incrementarem-se os conteúdos básicos abordando assuntos políticos, econômicos e jurídicos, Direitos Humanos, bem como conceitos e reflexões éticas. Outra proposta pode ser encontrada em La Taille (2009), para quem o trabalho de educação moral deve privilegiar as virtudes justiça, generosidade e honra. O mesmo autor não descarta a importância do trabalho com a polidez, a honestidade, entre outros valores. No entanto, ele alerta que a educação em valores morais não deve confundir-se com o desenvolvimento de um "leque de virtudes". Resta dizer que, para o aludido autor, o trabalho com virtudes morais e outras a elas relacionadas é importante devido ao fato de elas poderem ocupar lugar de destaque na construção das representações de si.

Pode-se citar, como exemplo, a polidez que, de acordo com Comte-Sponville (2009), é a porta de entrada para as demais virtudes. Para La Taille (2001), a polidez não pressupõe sinceridade e nem exige reflexão, mas é uma ação que sinaliza respeito e consideração pelo outro. Diante disso, o autor realizou uma pesquisa (La Taille, 2001) a fim de investigar as relações entre a polidez e o desenvolvimento moral. Participaram do estudo 90 alunos de uma instituição particular, separados em três grupos, igualmente divididos quanto à idade: 6,9 e 12 anos. Por sua vez, cada grupo de 30 sujeitos foi dividido quanto ao sexo: 15 meninos e 15 meninas. Foram realizadas entrevistas clínicas com perguntas abertas e situações-problema. Dentre os resultados encontrados, o autor averiguou que a polidez pertence ao universo moral das crianças de seis a 12 anos. De uma forma geral, os dados sugerem que a polidez tem lugar relevante na gênese da moralidade. Assim, diante dos resultados, La Taille (2001) afirma que a polidez está credenciada para constar dos valores a serem trabalhados pela educação em valores morais.

Como exposto, muitos são os temas que podem ser abordados na formação moral dos alunos. Do mesmo modo, muitos procedimentos podem ser adotados na condução de práticas na referida formação. Sobre este aspecto, é importante dizer que dependendo de como é conduzida a educação em valores morais, ela favorecerá comportamentos de maneiras distintas (Piaget, 1930/1996).

Dentre os procedimentos que podem ser utilizados, destaca-se o convívio escolar (La Taille, 2009; Secretaria de Educação Fundamental, 2000), isto é, a qualidade das relações sociais que são estabelecidas na escola, a qual exerce papel fundamental no que concerne à educação em valores morais. Segundo os PCNs (Secretaria de Educação Fundamental, 2000), a melhor experiência moral que o aluno pode vivenciar é o convívio respeitoso na escola. A ênfase deve estar em praticar, no dia a dia, as questões morais refletidas, "pois nada substitui o exercício da vida moral, tanto do ponto de vista intelectual quanto do afetivo" (La Taille, 2009, p. 256). Assim, as atividades cooperativas ganham destaque no que diz respeito à formação moral devido ao fato de ser a base para a construção da autonomia (Piaget, 1930/1996; Puig, 2007). É importante mencionar, ainda, que tal procedimento pode ser realizado em qualquer ano escolar, ou seja, também nos anos iniciais, pois, conforme bem discute La Taille (2009), não se pode esperar até o ensino médio para ajudar os alunos a refletir sobre a moral. 
Por fim, considera-se relevante citar três pesquisas que investigaram a educação em valores morais no contexto escolar. A primeira delas diz respeito ao estudo de Müller (2008), no qual, dentre outros objetivos, a autora pesquisou como professoras de $5^{\mathrm{a}}$ a $8^{\mathrm{a}}$ série do ensino fundamental ensinam a justiça em suas práticas pedagógicas. Para tanto, a referida pesquisadora entrevistou 20 docentes de escolas particulares de Vitória, Espírito Santo. Dentre os resultados alcançados, Müller (2008) constatou que todas as participantes consideram um dever ensinar a justiça em suas práticas pedagógicas, bem como relatam que ensinam o referido valor. A autora verificou, ainda, que a motivação maior para esta prática das docentes diz respeito ao fato de estarem contribuindo para uma sociedade melhor.

Dados semelhantes podem ser encontrados no levantamento de experiências "bem-sucedidas" de educação em valores morais realizado por Alencar, De Marchi, Couto, Romaneli e Lima (2014). Este estudo ocorreu por meio da aplicação de questionários, on-line e via correio, em profissionais da educação como diretores, coordenadores pedagógicos, professores e pedagogos. Chamou a atenção das pesquisadoras o baixo retorno de questionários: 92 de 734 enviados. Outro dado importante corresponde ao fato de que apenas 68 deles continham relatos de experiências. A partir dos dados coletados, dentre outros, as autoras averiguaram que a maior parte da amostra considera que a instituição escolar deve formar moralmente, assim como justifica com o argumento de que esta é uma função da escola.

Por sua vez, o estudo de Alencar, De Marchi, Couto, Romaneli e Lima (2013) descreve e discute três experiências de educação em valores morais. Foram realizadas entrevistas semiestruturadas com propositores e participantes das experiências. As pesquisadoras verificaram alguns limites, dificuldades, bem como pontos positivos e negativos das referidas experiências. Com relação às dificuldades e pontos negativos, Alencar et al. (2013) destacam: a descontinuidade dos projetos; a carência de avaliação formal e registro das avaliações informais acerca das atividades desenvolvidas; a resistência de profissionais em trabalhar com projetos e a ausência de formação específica dos profissionais envolvidos nas experiências. No que concerne aos pontos positivos das experiências analisadas, as autoras ressaltam os seguintes aspectos: análise do diagnóstico do problema a ser enfrentado; utilização de métodos democráticos e promoção de mudanças nas ações e juízos dos alunos.

Isto posto, ressalta-se que é necessária a busca por uma prática educacional que vise à formação moral e ética, tanto de crianças quanto de jovens e adultos (La Taille, 2006). Nesse sentido, no presente estudo objetivou-se verificar se professoras que lecionam para o $1^{\circ}$ e o $5^{\circ}$ ano do ensino fundamental consideram que ensinam a justiça em suas práticas pedagógicas e, se positivo, qual a motivação para ensinar este valor moral. Além disso, buscou-se averiguar as diferenças entre dois grupos de entrevistadas, docentes de $1^{\circ}$ e de $5^{\circ}$ ano, com relação aos objetivos acima mencionados.

\section{Método}

\section{Participantes}

Participaram 23 professoras, sendo que 11 lecionavam para o $1^{\circ}$ ano e 12 para o $5^{\circ}$ ano do ensino fundamental, de 10 escolas públicas municipais da cidade de Vitória, Espírito Santo. Dentre as participantes, sete docentes encontravam-se entre 31 e 41 anos, 13 delas entre $42 e$ 52 anos e três entre 53 e 63 anos. Por sua vez, o tempo de formação universitária das entrevistadas variou entre seis e 32 anos, para os quais foram estipulados os intervalos entre 6 e 10 anos $(n=7)$, entre 11 e 15 anos $(n=8)$, entre 16 e 20 anos $(n=5)$ e acima de 21 anos $(n=5)$.

\section{Instrumento e Procedimentos}

As docentes foram selecionadas por meio de contato com instituições de ensino da rede municipal de Vitória. Inicialmente, foram escolhidas escolas localizadas em bairros de classe baixa do referido município, que resultou em um total de 30 instituições. A partir de um sorteio, elegeu-se a ordem dos colégios a serem contatados. Para 
compor a presente pesquisa, foi necessário visitar 10 instituições de ensino. Antes de abordar as participantes, a pesquisadora apresentou o estudo para a direção e/ou setor pedagógico da instituição, que assinou uma autorização para a realização da coleta de dados na escola.

Foram realizadas entrevistas individuais, semiestruturadas, tendo como referência o método clínico piagetiano (Piaget, 1932/1994, 1926/2005). O método clínico é um procedimento que se realiza por meio de entrevistas ou situações abertas, em que, por meio de uma intervenção sistemática do pesquisador frente à conduta dos participantes, busca-se acompanhar o curso do pensamento dos indivíduos. Há o pressuposto de que os sujeitos têm em mente representações da realidade e, sendo assim, o importante é fazer com que essas crenças espontâneas sejam emitidas por meio de perguntas adequadas (Carraher, 1998; Delval, 2002).

Dentre as perguntas do roteiro de entrevista, no presente trabalho foram analisadas as seguintes questões: você ensina justiça em suas práticas pedagógicas? Por quê? As entrevistas foram realizadas pela pesquisadora responsável pelo estudo, na própria instituição que a participante lecionava, em locais como a sala de aula, sala da direção, auditório, entre outros. Todas as entrevistas foram gravadas e, posteriormente, transcritas.

Os dados foram analisados com base na teoria piagetiana e na sistematização proposta por Delval (2002). Assim, com fundamento na referida proposta, adotou-se para a análise dos dados os seguintes passos: (a) transcrição de todas as entrevistas, (b) leitura de todas as entrevistas, (c) elaboração de categorias iniciais, (d) discussão das categorias iniciais com duas auxiliares de pesquisa, (e) elaboração de categorias detalhadas e resumidas e (f) discussão com uma juíza para validação das categorias. Após esta etapa, as entrevistas foram analisadas mediante as categorias elaboradas. Nesta última fase, contou-se com uma auxiliar de pesquisa e uma juíza para o fechamento da análise dos dados.

No decorrer da pesquisa, foram respeitados todos os procedimentos éticos conforme os pa- drões da Resolução N 196/1996 do Conselho Nacional de Saúde (1996). Assim, as professoras foram solicitadas a assinar um Termo de Consentimento Livre e Esclarecido. Vale dizer que, para respeitar o anonimato das entrevistadas, os trechos de entrevistas mencionados ao longo do texto são acompanhados de nomes fictícios, seguidos do ano escolar para o qual a participante lecionava. Ressalta-se, ainda, que os referidos trechos encontram-se entre aspas.

\section{Resultados e Discussão}

Todas as docentes $(n=23)$ consideram que ensinam a justiça em suas práticas pedagógicas, o que vai ao encontro dos dados obtidos na pesquisa de Müller (2008). As participantes do presente estudo emitiram 105 justificativas para a atitude de ensinar a justiça, tendo em vista que cada docente podia mencionar mais de uma justificativa. A partir dos dados coletados, foram estabelecidas 14 categorias, conforme exposto na Tabela 1.

A partir das justificativas enunciadas pelas professoras, foram elaboradas duas categorias que apontam para instituições que, segundo as docentes, têm a responsabilidade de educar sobre a justiça: a escola e a família. Portanto, a prática de ensino deste valor moral justifica-se pelo fato de essa ser uma responsabilidade da escola ou, ainda, devido à carência desse papel por parte da família.

Com relação à categoria função da escola, foram mencionados a referida instituição $(n=13)$ e o professor $(n=7)$ como responsáveis pela formação moral dos educandos. Constatou-se que grande parte dessas justificativas $(n=13)$ foi relatada por docente de $1^{\circ}$ ano:

Infelizmente, a escola foi, principalmente na época da ditadura e nos anos anteriores, muito pautada em preparar o sujeito para o vestibular. Mas, a escola se esqueceu de que aquele sujeito é um ser humano, ele precisa de valores, ele precisa de direitos. Então, a gente precisa trabalhar o ser humano que está comigo, ele precisa de formação. Não só preparar para o vestibular, preparar 
Tabela 1

Justificativas das Docentes para Ensinar a Justiça

\begin{tabular}{lcc}
\hline Justificativas & Número $(n)$ & Porcentagem (\%) \\
\hline 1. Função da escola & 20 & 19,0 \\
2. Crise de valores & 15 & 14,3 \\
3. Convivência em sociedade & 13 & 12,4 \\
4. Vivência diária & 8 & 7,6 \\
5. A família não cumprir esse papel & 6 & 5,7 \\
6. Sociedade precisar de regras & 5 & 4,8 \\
7. Futuro dos alunos & 5 & 4,8 \\
8. Desenvolvimento de seres humanos mais capazes, críticos e de caráter & 5 & 4,8 \\
9. Ensino da polidez aos alunos & 5 & 4,8 \\
10. Ensino aos alunos sobre o que é certo e errado & 5 & 4,8 \\
11. Necessidade de ensinar desde pequeno & 4 & 3,8 \\
12. Valores pessoais & 4 & 3,8 \\
13. Promoção de uma sociedade melhor & 3 & 2,9 \\
14. Outros & 7 & 6,7 \\
\hline Total & 105 & 100,0 \\
\hline
\end{tabular}

para o ENEM [Exame Nacional do Ensino Médio], etc. Tem que preparar para a vida. (Jacinta, $1^{\circ}$ ano)

Por outro lado, as justificativas cuja ênfase está em a família não cumprir esse papel sinalizam que a prática de ensino da justiça não é entendida por estas docentes como uma responsabilidade da escola ou do professor, mas sim da família, e como esta não está cumprindo tal papel, compete à escola assumir a função: "Como eu estou com as crianças na minha mão, eu penso que eles têm que ter, já que muitos não trazem esse senso de justiça de casa" (Judite, $1^{\circ}$ ano). No que concerne a este grupo de justificativas, as participantes de $1^{\circ}$ ano também foram as que emitiram maior número $(n=4)$.

Tais justificativas levantam uma questão: a quem compete o ensino de valores morais? Alguns podem dizer que é a família a principal responsável por esse tipo de formação, enquanto outros podem afirmar que a escola é espaço privilegiado para tal. No presente estudo, con- corda-se com Müller e Alencar (2012) quando pontuam que a educação em valores morais pode acontecer em diversos espaços sociais, dentre eles a família e a escola. Assim, ambas as instituições são imprescindíveis no que diz respeito a essa formação. Com relação à escola, diversos autores (García \& Puig, 2010; La Taille, 2009; Piaget, 1930/1996; Puig, 1998, 2007) têm destacado a sua importância para a referida educação, o que está em consonância com o que propõem os PCNs (Secretaria de Educação Fundamental, 2000).

Vale ressaltar que afirmar a escola como lugar propício para a educação em valores morais não equivale a destituir o papel da família na formação dos alunos. Nesse sentido, autores como Dessen e Polonia (2007) e García e Puig (2010) destacam a importância da aproximação entre esses dois contextos. Estes últimos autores ponderam, ainda, que incorporar as famílias à dinâmica escolar é um processo que requer tempo e dedicação. As possibilidades para a concretiza- 
ção dessa meta são variadas, e cada escola deve decidir quais lhe são mais adequadas (García \& Puig, 2010).

Na pesquisa de Alencar et al. (2014), também foi possível verificar esses dois tipos de justificativas com relação à afirmação de que é um dever da escola ensinar educação em valores morais. A justificativa "é função da escola" foi a mais citada entre os participantes e "a família não cumpre seu papel" foi o quinto argumento mais proferido. Também no estudo de Müller (2008), as participantes emitiram estas justificativas para fundamentar a consideração de que é um dever ensinar a justiça em sala de aula. Das justificativas obtidas, "cumprir a função de outros que não o fazem", sendo "outros" a família, foi a primeira em ordem de frequência e "ser uma função da escola" foi a segunda. Isto posto, nota-se que a educação em valores morais, o que inclui o ensino da justiça, parece ser compreendida pela maioria dos educadores como sendo uma função da escola. Além disso, nos dois estudos mencionados e na presente pesquisa, há destaque para a argumentação em torno da ausência do cumprimento deste papel por parte da família, o que leva a inferir que, para estes profissionais, a família também é responsável pela formação moral dos alunos, mas deixa esta função a cargo da escola.

Outro tipo de justificativa utilizada pelas docentes diz respeito à possível crise de valores existente na atualidade, seja com relação à sociedade de forma geral $(n=9)$ ou aos alunos em específico $(n=6)$. Assim, a motivação para o ensino da justiça encontra-se na necessidade de sanar um problema de ordem moral presente na sociedade. Da mesma forma que nas categorias anteriores, foram averiguadas diferenças entre os dois grupos de entrevistadas: das 15 justificativas obtidas, 12 foram enunciadas por docentes do $1^{\circ}$ ano. A explanação de Joseane ( $1^{\circ}$ ano) ilustra esse grupo de justificativas: "E a gente percebe nessa comunidade que alguns valores estão sendo esquecidos".

Essas justificativas trazem à tona a discussão proposta por La Taille e Menin (2009) sobre se na atualidade vive-se um momento de "crise de valores" ou de "valores em crise". De acordo com o relato das professoras, o tempo presente caracteriza-se por uma "crise de valores", em que os valores morais estão ausentes, enfraquecidos, e, devido a isso, elas ensinam a justiça. Vale mencionar que, assim como no presente estudo, no trabalho de Alencar et al. (2014) esse tipo de justificativa foi o segundo mais citado pelos participantes para explicar por que a escola deve oferecer educação em valores morais aos alunos.

Ainda sobre este tópico, La Taille (2009) alerta que, nos tempos atuais, as culturas do tédio e da vaidade sobrepõem-se às culturas do sentido e do respeito de si, o que resulta na precariedade das relações humanas e na superficialidade com que se trata o mundo e as pessoas. Diante deste quadro, La Taille (2011) adverte que a moral está prejudicada, uma vez que esta pressupõe o respeito pelas pessoas, o reconhecimento de sua dignidade e de seus direitos. Nesse sentido, La Taille $(2009,2011)$ destaca que é necessário que os responsáveis pela educação moral de crianças e de jovens, isto é, os adultos de forma geral e os profissionais da educação, empenhem-se para que as novas gerações penetrem numa cultura de sentido. Para tanto, é preciso cuidar do mundo, das crianças e dos jovens, resgatar a verdade, preservar a memória e articular conhecimento e sentido (La Taille, 2009).

É importante ressaltar o fato de que as entrevistadas também justificaram a prática do ensino da justiça com base nos próprios valores pessoais, ou seja, suas concepções e experiências de vida fazem com que considerem importante o ensino do valor em pauta. Analisando o presente grupo de justificativas, verifica-se que as docentes de $5^{\circ}$ ano argumentam dessa forma com maior frequência $(n=3)$ do que as professoras de $1^{\circ}$ ano $(n=1)$. O discurso de Letícia ( $5^{\circ}$ ano) exemplifica esta categoria:

Porque é o que eu te falei. A pessoa, ela repassa, ela passa aquilo que ela aprendeu. Então, se eu busco isso é porque no decorrer dos meus anos, tanto na minha educação familiar, quanto na minha educação escolar, eu fui adquirindo $e$ entendendo que isso é necessário, que isso faz parte dos valores. 
Esse tipo de justificativa chama a atenção para a formação das docentes no que concerne aos valores a serem ensinados na educação em valores morais. Os PCNs (Secretaria de Educação Fundamental, 2000) propõem o trabalho com a Ética, sendo eleitos quatro conteúdos para o referido assunto: respeito mútuo, justiça, diálogo e solidariedade. Por sua vez, diferentes autores sugerem variados temas (La Taille 2006, 2009; Puig, 2007). Portanto, muitos conteúdos podem ser ensinados pelos educadores. Deve-se sublinhar, no entanto, que a escolha de temas para uma proposta de formação moral deve estar pautada em características próprias de cada comunidade escolar. Como exemplo, pode-se citar as três experiências analisadas por Alencar et al. (2013), nas quais foram trabalhados temas diferentes, e de formas distintas, a fim de atingir objetivos delineados em busca de respostas a problemas sociomorais contextuais. Assim, pelo o que foi exposto, é importante ressaltar que, tendo em vista a complexidade que envolve a formação moral, considera-se que a escolha de temas para esta educação não deve ficar somente a cargo da escolha subjetiva de cada professor, ou seja, a partir de seus valores e critérios pessoais. Ao contrário, os assuntos a serem abordados devem ser escolhidos por meio de uma discussão entre toda a comunidade escolar. Além disso, é relevante que a referida discussão e escolha tenham como base critérios de autores da área da Psicologia da Moralidade e da Educação em valores morais, bem como é importante que os temas escolhidos sejam incluídos no projeto político pedagógico da escola.

Entre os dados obtidos, houve, ainda, três grupos de justificativas que versam sobre a importância do ensino da justiça para a sociedade, porém abordando distintos aspectos, a saber: convivência em sociedade, sociedade precisar de regras e promoção de uma sociedade melhor. Esses argumentos somam um total de 20,1\% $(n=21)$ das justificativas obtidas, o que leva a constatar que este é um ponto relevante para as docentes no que concerne à motivação para o ensino da justiça.

As entrevistadas mencionaram que ensinam a virtude em pauta pela convivência em socie- dade, isto é, para as participantes, o ensino da justiça contribui para uma boa convivência social: "É importante porque o ser humano é um ser social, e você ser um ser social, você tem que saber comportar-se, você tem que ter atitude para se dirigir ao seu próximo, para conviver" (Luana, $5^{\circ}$ ano). As professoras que trabalham com o $5^{\circ}$ ano foram as que mais emitiram as justificativas incluídas nesta categoria $(n=8)$. Este tipo de explicação demonstra que as docentes, ao ensinarem a justiça em suas práticas pedagógicas, visam favorecer a aprendizagem ética "aprender a conviver" (Puig, 2007), que equivale à tarefa formativa que objetiva ajudar os indivíduos a estabelecer vínculos pessoais baseados na compreensão dos outros. Como nas categorias anteriores, também foi encontrado este tipo de justificativa na pesquisa de Alencar et al. (2014), em que "contribui para a vivência social" foi a terceira justificativa mais relatada pelos profissionais para argumentar por que a escola deve educar em valores morais. Por sua vez, no trabalho de Müller (2008), "organizar a sociedade" foi justificativa emitida pelas docentes para a questão sobre por que devem ensinar a justiça.

As docentes disseram, também, que ensinam a justiça pelo fato de a sociedade precisar de regras. Em outras palavras, constatou-se que elas entendem que, ensinando o referido valor, estão contribuindo para que os seres humanos de forma geral, e os alunos em específico, aprendam a respeitar e a seguir as regras, e aprendam a cumprir seus deveres:

Porque sem justiça como que o mundo fica?

Se não houver justiça, as leis vão ser feitas como? Como vão ter as normas e as regras da sociedade? ... O cidadão tem que seguir algumas normas e regras. A gente gostaria de ser como a gente queria, não é? Mas não pode, tem que ser uma coisa feita para que todos possam alcançar. (Laís, $5^{\circ}$ ano)

Os deveres morais representam uma necessidade social, pois sem eles o convívio entre os indivíduos seria inviável. Desse modo, verifica-se a relevância de que o sistema educacional trabalhe as regras morais. O mais importante, no entanto, reside no fato de refletir sobre os princípios que inspiram as regras de convívio. Assim, os pro- 
fissionais da educação podem contribuir ajudando os alunos a refletirem sobre tais princípios.

Por último, um grupo menor de justificativas sobre a importância da justiça para a sociedade aponta para a promoção de uma sociedade melhor como motivação para o ensino da justiça: "Porque a gente acredita que através da formação de um cidadão melhor, de uma criança que vai se tornar um cidadão, que a gente vai ter um mundo melhor" (Janaina, $1^{\circ}$ ano). No trabalho de Alencar et al. (2014) também foi constatado esse tipo de motivo entre as justificativas emitidas sobre ser um dever da escola ensinar a educação em valores morais. Já na pesquisa de Müller (2008), a justificativa "para contribuir para uma sociedade melhor" foi a que as professoras relataram em maior frequência para fundamentar por que ensinam a justiça em suas práticas pedagógicas.

Além das categorias anteriormente discutidas, foram constatadas justificativas que remetem à possibilidade de expansão de si (La Taille, 2006) como motivação para ensinar a justiça. Tal aspecto pode ser notado nas categorias futuro dos alunos e desenvolvimento de seres humanos mais capazes, críticos e de caráter. No que concerne à categoria futuro dos alunos, a consideração de Júlia ( $1^{\circ}$ ano) é exemplo característico: "Para que ele possa viver em um mundo mais justo e ver que ele pode construir alguma coisa melhor sozinho, pelas próprias mãos, e não pelo meio que vive". Essa justificativa também foi constatada no estudo de Müller (2008) entre as explicações relatadas pelas participantes para argumentar por que ensinam a justiça em suas práticas pedagógicas. Por sua vez, com relação à categoria desenvolvimento de seres humanos mais capazes, críticos e de caráter, foram averiguadas menções ao desenvolvimento das capacidades dos indivíduos $(n=1)$, ao desenvolvimento de sujeitos críticos $(n=2)$ e ao desenvolvimento das características do caráter $(n=2)$. Segundo La Taille (2006), a possibilidade de expansão de si próprio é condição necessária para que a vida faça sentido, e o invariante psicológico do plano ético corresponde à busca de sentido para a vida. Dessa maneira, ressalta-se a relevância deste dado no que diz respeito à educação em valores morais, uma vez que tal prática deve, também, ajudar as crianças e os jovens a construírem seus projetos de vida, e que esta seja uma vida boa, com e para outrem.

A vivência diária também serviu de justificativa para as professoras, sendo a maioria $(n=5)$ participante que lecionava para o $5^{\circ}$ ano. Esse grupo contém as justificativas que tratam a justiça como um valor que permeia os acontecimentos do dia a dia. Eis ilustração desse tipo de explicação: "Porque a justiça é fundamental no nosso dia a dia, não é? E tudo envolve justiça, assim, relacionamentos humanos, não é?" (Lau$\mathrm{ra}, 5^{\circ}$ ano). As explicações incluídas nesse grupo remetem a uma questão importante no que se refere à educação em valores morais: o convívio escolar (La Taille, 2009; Secretaria de Educação Fundamental, 2000). Como o exposto, a justiça é entendida por essas docentes como um valor que está presente nos acontecimentos do dia a dia. Dessa forma, é necessário estar atento a tais vivências, para que as relações no ambiente escolar sejam pautadas na cooperação, no respeito mútuo, na justiça, entre outros valores.

Por sua vez, as docentes afirmam que ensinam a justiça pelo ensino da polidez aos alunos, isto é, pela possibilidade de que, por meio do ensino da justiça, os alunos adquiram boas maneiras, mudem seus maus hábitos, manias. A polidez, conforme afirma Comte-Sponville (2009), é a porta de entrada para as demais virtudes e, segundo La Taille (2001), ela exerce papel importante no despertar da gênese da moralidade infantil. Em seu estudo sobre a referida virtude, La Taille (2001) averiguou, dentre outros aspectos, que a polidez pertence ao universo moral de crianças entre seis e 12 anos. Diante disso, o autor adverte que a educação não pode ignorar o fato de que a criança pequena elege o tema da polidez como assunto de reflexão. Além disso, o autor argumenta que por se tratar de um conjunto de regras simples, a polidez pode integrar o universo moral infantil, sendo adequada aos níveis inferiores de desenvolvimento moral, isto é, à heteronomia (Piaget, 1932/1994) ou ao nível pré-convencional (Kohlberg, 1992). Embora em 
pequeno número, os dados da presente pesquisa apontam para este tipo de preocupação por parte de algumas participantes. É necessário destacar, porém, que a educação em valores morais não deve se confundir com o desenvolvimento de um "leque de virtudes" (La Taille, 2009) e deve ser trabalhada mediante procedimentos que favoreçam o alcance da autonomia (Piaget, 1930/1996).

Além dos dados descritos, as participantes justificaram suas práticas pela necessidade de ensinar desde pequeno. Para estas professoras, os alunos precisam aprender sobre a justiça desde pequenos. As docentes de $1^{\circ}$ ano foram as que mais emitiram esse tipo de motivo $(n=3)$. Este dado está em consonância com a perspectiva teórica adotada no presente estudo, a teoria piagetiana, em que há a concepção de que um indivíduo torna-se moral por meio de um processo de construção, passando da anomia para a heteronomia, podendo alcançar a autonomia (Piaget, 1932/1994). De acordo com esta teoria, há um desenvolvimento do juízo moral, cujo despertar ocorre em torno dos quatro anos de idade. Dessa maneira, concorda-se com La Taille (2009) quando afirma que a escola não pode esperar até o ensino médio para ajudar os alunos a refletir sobre a moral.

Outra justificativa utilizada foi o ensino aos alunos sobre o que é certo e errado, sendo ressaltado o trabalho com os temas drogas, respeito, bullying, união entre pessoas e capacidade de ouvir para compreender o que é certo. Este dado foi mencionado somente por professoras de $5^{\circ}$ ano. Por último, constatou-se a categoria outros, em que foram agrupadas justificativas tais como a ausência do ensino da justiça por parte da mídia, a obrigação da participante como cidadã, a felicidade do aluno, entre outras.

\section{Considerações Finais}

Frente aos dados, destaca-se que, para as participantes, o ensino da justiça pode estar relacionado à possibilidade de expansão de si (La Taille, 2006). Sobre este aspecto, vale ressaltar as discussões realizadas por La Taille (2006), para quem a possibilidade de expansão de si próprio é condição necessária para que a vida faça sentido, isto é, corresponde ao invariante do plano ético. Nessa perspectiva, é de suma importância para a construção de personalidades éticas que valores morais, como a justiça, sejam conteúdos associados às representações de si dos indivíduos. Tal associação, no entanto, dependerá das respostas que a pessoa forneceu no plano ético, ou seja, das respostas à pergunta "que vida eu quero viver?". Dito de outra forma, se ser justo corresponde a uma opção ética do sujeito, a justiça fará parte das suas opções morais. Para que isso ocorra, é necessário que a justiça faça parte dos valores que dão sentido à vida do indivíduo, que ele se veja como pessoa de valor agindo justamente. Nisto reside a importância da educação em valores morais no contexto escolar, a qual deve propiciar a construção de indivíduos autônomos, que se guiem por princípios de justiça.

Além disso, na presente investigação, foram constatados conteúdos que versam sobre valores. Tal dado pode ser averiguado nas justificativas crise de valores e valores pessoais. Diante desses dados, destaca-se que, se há uma crise de valores na atualidade, em que os valores morais estariam ausentes, como definem La Taille e Menin (2009), tal situação reforça a importância que deve ser dada à educação em valores morais, isto é, à escolha de temas e de procedimentos para este tipo de formação. Como exposto, não é qualquer tipo de valor que deve ser trabalhado na formação moral dos alunos, bem como não é qualquer procedimento que promoverá a construção de indivíduos autônomos (Piaget, 1930/1996). Ressalta-se, então, que a escolha dos valores a serem trabalhados e dos procedimentos a serem adotados não deve ficar somente a cargo da seleção subjetiva de cada professor. É importante chamar a atenção, também, para a relevância que os cursos de formação de professores têm no que diz respeito ao ensino de valores morais no contexto escolar. Nesse sentido, entende-se que há necessidade de que os cursos de graduação e formação preparem esses profissionais para que eles sejam capazes de trabalhar tais temas. 
Por sua vez, destaca-se que as participantes também mencionaram conteúdos que versam sobre a família. As docentes do presente estudo relataram uma queixa com relação à ausência de participação da família na educação dos alunos. Sobre este aspecto, assinala-se, com Müller e Alencar (2012), que a formação moral pode acontecer em diversos espaços sociais, como a família e a escola. Assim, concorda-se com autores (Dessen \& Polonia, 2007; García \& Puig, 2010) que destacam a importância da aproximação entre esses dois contextos para a formação dos educandos.

Finalmente, com relação às diferenças entre os dados dos anos escolares pesquisados, de forma geral, foi constatado que as docentes que trabalham com o $1^{\circ}$ ano tendem a justificar o ensino da justiça predominantemente devido ao fato de esta ser uma prática de responsabilidade da escola, seja porque faz parte da própria função da instituição escolar ou porque a família não está cumprindo essa função. Por sua vez, as participantes que lecionam para o $5^{\circ}$ ano parecem ensinar a justiça porque esta prática pode favorecer a convivência em sociedade, as relações humanas. Diante disso, pode-se colocar a seguinte questão: por que as docentes que trabalham com o $5^{\circ}$ ano tendem a embasar suas práticas nas relações interpessoais? Dentre outros aspectos, pondera-se que tal situação pode ser decorrente da etapa de desenvolvimento dos educandos das docentes, isto é, os alunos de $5^{\circ}$ ano podem estar apresentando comportamentos mais conflituosos do que aqueles de $1^{\circ}$ ano. No entanto, novas pesquisas devem ser realizadas para que este aspecto seja mais bem investigado.

Com esse estudo, espera-se contribuir para a implantação de políticas públicas que visem à melhoria da qualidade da educação em valores morais no contexto escolar, especialmente no que concerne ao ensino da justiça. Nesse sentido, ressalta-se a necessidade de um trabalho contínuo de ensino da justiça, que envolva todos os anos escolares e que seja pensado e programado para desenvolver indivíduos autônomos, aptos à cooperação (Piaget, 1930/1996).

\section{Referências}

Alencar, H. M., De Marchi, B. F., Couto, L. L. M., Romaneli, M. S., \& Lima, M. G. (2013). Educação em valores morais: Uma análise de três experiências no Espírito Santo. In M. S. S. Menin, P. U. R. Bataglia, \& J. A. M. Zechi (Eds.), Projetos bem-sucedidos de Educação em valores: Relatos de escolas públicas brasileiras (pp. 238-272). São Paulo, SP: Cortez.

Alencar, H. M., De Marchi, B. F., Couto, L. L. M., Romaneli, M. S., \& Lima, M. G. (2014). Educação em valores morais: Juízos de profissionais no contexto escolar. Psicologia Escolar e Educacional, 18(2), 255-264. doi:10.1590/ 2175$3539 / 2014 / 0182742$

Biaggio, A. M. B. (2006). Lowrence Kohlberg: Ética e Educação Moral (2. ed.). São Paulo, SP: Moderna.

Carraher, T. N. (1998). O método clínico: Usando os exames de Piaget. São Paulo, SP: Cortez.

Comte-Sponville, A. (2009). Pequeno tratado das grandes virtudes (2. ed.). São Paulo, SP: Martins Fontes.

Conselho Nacional de Saúde. (1996). Resolução 196/96, de 10 de outubro de 1996. Aprova as diretrizes e normas regulamentadoras de pesquisas envolvendo seres humanos. Brasília, DF: Autor. Recuperado em www.conselho.saude. gov.br/

Delval, J. (2002). Introdução à prática do método clínico: Descobrindo o pensamento das crianças (F. Murad, Trad.). Porto Alegre, RS: Artmed.

Dessen, M. A., \& Polonia, A. C. (2007). A família e a escola como contextos de desenvolvimento humano. Paidéia (Ribeirão Preto), 17(36), 2132. doi:10.1590/S0103-863X2007000100003

García, M. X., \& Puig, J. M. (2010). As sete competências básicas para educar em valores (O. Curros, Trad.). São Paulo, SP: Summus.

Kohlberg, L. (1992). Psicologia del desarrollo moral. Bilbao, España: Desclée de Brouwer

La Taille, Y. (2001). Desenvolvimento moral: A polidez segundo as crianças. Cadernos de Pesquisa, 114, 89-119. doi:10.1590/S010015742001000300004

La Taille, Y. (2006). Moral e ética: Dimensões intelectuais e afetivas. Porto Alegre, RS: Artmed. 
La Taille, Y. (2009). Formação ética: Do tédio ao respeito de si. Porto Alegre, RS: Artmed.

La Taille, Y. (2011). A moral e a cultura do tédio. In J. G. Aquino, R. Sayão, S. Rizzo, \& La Taille, Y, Família e educação: Quatro olhares (pp. 5175). Campinas, SP: Papirus.

La Taille, Y., \& Menin, M. S. S. (2009). Introdução. In Y. La Taille \& M. S. S. Menin (Eds.), Crise de valores ou valores em crise? (pp. 9-13). Porto Alegre, RS: Artmed.

Müller, A. (2008). Educação em valores morais: $O$ aprender e o ensinar sobre justiça (Dissertação de mestrado, Universidade Federal do Espírito Santo, Vitória, ES, Brasil).

Müller, A., \& Alencar, H. M. (2012). Educação moral: O aprender e o ensinar sobre justiça na escola. Educação e Pesquisa, 38(2), 453-468. doi:10.1590/S1517-97022012000200012

Piaget, J. (1962). The relation of affectivity to intelligence in the mental development of child. Bulletin of the Menninger Clinic, 26(3), 129-137. (Original work published 1954)

Piaget, J. (1994). O juízo moral na criança (4. ed., E. Leonardon, Trad.). São Paulo, SP: Summus. (Original publicado em 1932)
Piaget, J. (1996). Os procedimentos da Educação Moral. In L. Macedo (Ed.), Cinco estudos de Educação Moral (pp. 1-36). São Paulo, SP: Casa do Psicólogo. (Original publicado em 1930)

Piaget, J. (2005). Introdução: Problemas e métodos. In J. Piaget, A representação do mundo na criança (A. U. Sobral, Trad., pp. 9-31). Aparecida, SP: Ideias \& Letras. (Original publicado em 1926)

Puig, J. M. (1998). Ética e valores: Métodos para um ensino transversal (A. V. Fuzatto, Trad.). São Paulo, SP: Casa do Psicólogo.

Puig, J. M. (2007). Aprender a viver. In V. A. Arantes (Ed.), Educação e valores: Pontos e contrapontos (pp. 65-106). São Paulo, SP: Summus.

Secretaria de Educação Fundamental. (2000). Parâmetros Curriculares Nacionais. Apresentação dos Temas Transversais: Ética (Vol. 8, 2. ed.). Rio de Janeiro, RJ: DP\&A.

Recebido: $24 / 02 / 2014$

$1^{a}$ revisão: $30 / 06 / 2014$

$2^{a}$ revisão: $22 / 08 / 2014$

Aceite final: 25/08/2014 